\title{
LA PERICIA ANTROPOLÓGICA EN LA ARAUCANÍA DE CHILE. ENTRE TEORIAS Y PRACTICAS, 2003 - 2014
}

Anthropological expertise in the Araucanía of Chile. Between theories and practi-

ces, $2003-2014$

\section{MARCELO BERHO*, PAULO CASTRO** Y FABIEN LE BONNIEC***}

\section{Fecha de recepción: 24 de agosto de 2016 -Fecha de aprobación: 21 de octubre de 2016}

\section{Resumen}

La pericia antropológica está adquiriendo cada vez más importancia en la justicia penal chilena, según lo evidencia el número creciente de peritajes antropológicos solicitados por la Defensoría Penal Pública. Sin embargo, se puede observar que actualmente en Chile no existe realmente un modelo para su elaboración, uso y comunicación por parte de litigantes y peritos. De este hecho, resultan una variedad de maneras de elaborar y presentar esta prueba pericial, por lo que es necesario indagar y desarrollar una reflexión en torno a los distintos usos y concepciones que tiene el peritaje antropológico. Para esto, por una parte, se ha revisado la literatura antropológica y jurídica sobre los usos del peritaje antropológico en Chile y América Latina. Por otra parte, se ha analizado un corpus de casos penales donde se recurrió a peritajes antropológicos, entre 2003 y 2014, en La Araucanía. Por último, se presentan dos casos que permiten destacar tendencias, potencialidades y límites en el campo del peritaje antropológico.

Palabras claves: peritaje antropológico, prueba judicial, defensa penal indígena, modelo de gestión de peritaje antropológico, La Araucanía

\section{Abstract}

Anthropological expertise is becoming increasingly important in the Chilean criminal justice, as evidenced by the growing number of anthropological expert reports requested by the Public Defender's Office. However, we can see that today in Chile, litigants and experts don't have a model for processing, use and communication anthropological expertise. There is a variety of ways to prepare and present such expert evidence, so it is necessary to investigate and develop a reflection on the different uses and conceptions of anthropological expertise. On the one hand, it has been revised anthropological and legal literature on the use of anthropological expertise in Chile and Latin America. On the other hand, we have analyzed a corpus of criminal cases where they recourse to anthropological expert reports, between 2003 and 2014, in the Araucania region, this quantitative study has been put in perspective with two case studies, allowing highlight certain trends, potencies and limits in the work of anthropological expert.

Keywords: Anthropological expertise, judicial evidence, indigenous criminal defense, Management model expert of anthropological evidence, La Araucanía

* Licenciado en Antropología, Universidad Católica de Temuco, Doctor en Ciencias Sociales. Director del Centro de Estudios Socioculturales, Universidad Católica de Temuco y director del proyecto Fondef ID14I10379. Temuco, Chile.

Correo-e: mberhoc@gmail.com

** Licenciado en Antropología, Universidad Austral de Chile, Doctor en Antropología, Universidad Autónoma de Barcelona. Investigador del proyecto Fondef ID14I10379. Temuco, Chile. Correo-e: detranshumante@yahoo.es

*** Doctor en Antropología social y etnología, Escuela de Altos Estudios de París. Investigador del Núcleo de Estudios Intertétnicos e Interculturales, Universidad Católica de Temuco, y director alterno del proyecto Fondef ID14I10379. Temuco, Chile. Correo-e:fabien@uct.cl 


\section{Introducción}

La reforma procesal penal ${ }^{1}$ y el estilo histórico de relaciones interétnicas conflictivas entre chilenos y mapuche en el sur de Chile, han abierto el escenario para el reconocimiento de los derechos indígenas el seno de los tribunales estatales. En este marco, en la región de La Araucanía se observa un proceso de institucionalización de actores y mecanismos jurídicos especializados, como la Defensoría Penal Pública (en adelante DPP) y Defensoría Penal Mapuche (DPM), los abogados defensores y los facilitadores interculturales. Otra figura que se ha popularizado en los tribunales, en este escenario, es la del/la perito antropólogo/a. Si bien la participación de estos en los tribunales chilenos no es reciente, como lo atestiguan los casos judiciales de Juana Catrilaf en 1953 y de María Luisa Namuncura en 1960, su presencia hoy en día es más visible y frecuente ${ }^{2}$. Sin embargo, la introducción del discurso antropológico en la arena jurídica chilena, caracterizada por su carácter monocultural, no ha ocurrido sin provocar controversias y desencuentros. Estas tensiones son parte del debate latinoamericano en torno al reconocimiento, no solo jurídico sino político y social de las diferencias socioculturales, a la vez que participan del desarrollo de las antropologías del sur, las que no han sido ajenas a las demandas indígenas, especialmente mapuche.

Dentro de los elementos que configuran el actual estado del campo del peritaje antropológico en Chile, la ratificación en 2008 y la aplicación del Convenio 169 de la Organización Internacional del Trabajo en 2009, son hechos insoslayables. Desde fines de la década de 1990, se ha desarrollado un movimiento mapuche enfocado en la reivindicación de tierras y territorios que ha desatado la judicialización de las comunidades, organizaciones y personas mapuche como respuesta del Estado. Esta situación atenta contra el ejercicio legítimo de los derechos de los pueblos indígenas y tribales que consagra el Convenio 169 y otros instrumentos internacionales del bloque de constitucionalidad y, en general, limitan el reconocimiento de los derechos a las diferencias socioculturales. Predominará, por lo tanto, un contexto socio-jurídico caracterizado simultáneamente por la afirmación y la incomprensión de las diferencias. En esta tesitura, el/la antropólogo/a emergen como un puente necesario entre las distintas perspectivas, prácticas y éticas que se despliegan en el proceso judicial.

En este contexto, abordamos el peritaje antropológico en tanto prueba jurídica y forma de conocimiento antropológico, dando cuenta de la recepción que ha tenido en las cortes latinoamericanas y chilenas. En una segunda parte, compartimos los resultados preliminares de un estudio cuantitativo y cualitativo acerca de los usos de los peritajes antropológicos en La Araucanía. Además, se presentan dos casos de peritaje antropológico que permiten abrir la discusión respecto a los problemas que se presentan en su aplicación en el contexto de la cultura jurídica chilena. Esta perspectiva continental, nacional y regional sobre la pericia antropológica nos permitirá concluir con algunas reflexiones en torno al quehacer de las/los peritos antropólogos, y la relación existente entre conocimiento antropológico y el mundo jurídico. 


\section{Contexto y método de la investigación}

Con la reforma procesal penal en La Araucanía y Chile, se ha podido observar un interés creciente de parte de los abogados defensores de la DPP, por desarrollar teorías de casos que incorporen dimensiones socioculturales en la construcción argumental. Al llevar estos argumentos al litigio, se han encontrado con resistencias hacia los peritajes antropológicos por parte de las cortes de justicia. En este marco, un equipo del Centro de Estudios Socioculturales (CES) de la Universidad Católica de Temuco, está desarrollando un proyecto de investigación aplicada orientada a elaborar un modelo de gestión de peritaje antropológico (MoGPA) que en última instancia fortalezca los servicios de la defensa penal pública en contextos de diversidad cultural en La Araucanía, Chile ${ }^{3}$.

La primera fase de esta investigación aplicada se abocó a levantar un estado del arte de las experiencias existentes en el continente. El estado del arte consistió en el fichaje de 39 textos (libros, artículos, tesis, informes y ponencias) relacionados con los peritajes antropológicos y el pluralismo jurídico en América Latina y Chile. Se incluyó, además, la revisión de literatura especializada referida a América del Norte, Australia y Europa. El trabajo de fichaje consistió en tratar de responder algunas preguntas relevantes para la elaboración del MoGPA, como la visión de los agentes jurídicos sobre los peritajes antropológicos y el mundo indígena, el rol del antropólogo y de los peritajes antropológicos en el marco de la justicia penal, y las contribuciones y perspectivas teórico-metodológicas del peritaje antropológico en la actualidad.

La segunda fase de la indagación consistió en el estudio cuantitativo y cualitativo de un total de 44 causas penales en las que la defensa pública de La Araucanía solicitó peritaje antropológico, entre 2003 y 2014. Cada "causa" se definió como tal a partir de: 1) las solicitudes formales de peritaje antropológico que realizan las/los defensores públicos y licitados, previa aprobación de la Unidad de Estudios de la DPP; 2) los informes periciales elaborados por los antropólogos; y 3) las sentencias penales dictadas por jueces en el marco de un proceso penal, ya sea a través de un juicio oral o juicio abreviado. Durante esta fase también se desarrollaron entrevistas $y$ talleres grupales con defensores, facilitadoras interculturales, peritos antropólogos, dirigentes y autoridades tradicionales mapuche, y se realizaron seminarios y congresos académicos en los que se han ido socializando los avances del proceso de investigación.

\section{El peritaje antropológico en América Latina y Chile}

El peritaje antropológico remite a un conjunto de prácticas y conocimientos pertenecientes a las ciencias antropológicas: dependiendo de la rama de conocimiento antropológico que se desarrolle, cuenta con un objeto sobre el cual existe respaldo teórico y empírico, y tiene una expresión metodológica disciplinaria o interdisciplinaria. Este hecho se distribuye de manera variable en América Latina, dependiendo de los desarrollos científicos y del nivel de vinculación entre ciencia y sociedad que existe en cada país. El tipo de peritaje antropológico más frecuente en los países latinoamericanos se enfoca en materias socioculturales y particularmente en el conocimiento de la alteridad indígena.

En el plano jurídico, el peritaje antropológico representa un tipo particular de prueba jurídica que pueden usar las partes involucradas 
en un proceso judicial. En América Latina, el peritaje antropológico participa principalmente en procesos penales, en los cuales puede ayudar a conformar una determinada convicción acerca de las materias sobre las cuales se dirime. El ingreso del peritaje antropológico en los tribunales penales latinoamericanos se produce progresivamente desde los años setenta del siglo XX, en países como Colombia (Sánchez Botero, 2010) y Perú (Guevara Gil, 2015). En cada escenario, se establecen expectativas distintas acerca del peritaje antropológico. En México, por ejemplo, los autores plantean que las/los peritos antropólogos se dedican a comprender e interpretar conductas y hechos (Valladares, 2009), establecer sistemas de derecho propio y acreditar la pertenencia indígena (Fabre, 2011). Garza (2014), advierte sobre el uso del peritaje antropológico para justificar el atraso cultural atribuido por jueces monoculturales a los actuales indígenas de México.

Respecto de Colombia, Sánchez Botero (2010) conceptualiza la práctica pericial de los antropólogos como una mediación interpretativa de las realidades culturales que conviven en las fronteras estatales. Dicha mediación consiste en la exposición y evaluación que el antropólogo realiza de los hechos en el marco de la integralidad de una cultura. Según la autora, "el perito antropólogo es un colaborador técnico [...] llamado para establecer las causas que originaron un hecho, su efecto y la posibilidad de determinar si este ocurrió o pudo ocurrir" (Ibíd.: 96). El perito antropólogo puede ofrecer pruebas como perceptor, para referirse como experto frente a determinadas clases de hechos. O bien, puede actuar como evaluador que visualiza daños y perjuicios con respecto a los hechos.
Según Ávila Linzán (2011), en Ecuador los peritos antropólogos se ocupan de informar sobre las costumbres indígenas y esclarecer los conceptos socioculturales de estos en las cortes. En este sentido,

“(...) las pericias antropológicas consisten en un elemento importante para comunicar los códigos culturales al sistema de justicia entre los diversos colectivos (no solo los indígenas) con el fin de procesarlos a través de decisiones más cercanas a la realidad y diversidad social, que sean legitimadoras de su actuación y que influyan estratégicamente en los problemas estructurales que sostienen y toleran una sociedad inequitativa y antidemocrática" (Ibíd.: 33).

En Perú, las/los peritos antropólogos determinan la pertenencia cultural de una persona y establecen si esa pertenencia lo hizo o no actuar ilícitamente (Guevara, 2015). Los autores advierten que, sobre la tendencia de estos a hacer apología en favor de los indígenas, sin informar realmente acerca de las culturas de estos y el modo en que ellas condicionaron su acción (Guevara Gil, 2015; Verona, 2015). En lugar de esto, proveen descripciones generales de la cultura y pierden de vista su relación con el procesado. Las/los peritos antropólogos a veces obvian aspectos esenciales de los peritajes, como por ejemplo el que estén referidos a los sujetos y sus contextos de vida; otras veces opinan e incluso evalúan la conducta o las normas jurídicas (Verona, 2015).

En Argentina encontramos que la/el perito antropólogo es quien, dentro del juicio penal, se ocupa del conocimiento cultural de los relatos, biografías y contextos de ofensa marcados por la diversidad sociocultural (Kalinsky, 2000; Kalinsky \& Cañete, s/f). 
En Chile, en tanto apoyan o dan sustento a la teoría del caso en la defensa indígena (Lillo, 2010), acreditan costumbres y afirman la pertenencia indígena, así como el arraigo basado en vínculos sociales y territoriales (Álvarez, 2014; Rodríguez, 2012).

De acuerdo a nuestro acercamiento al peritaje antropológico practicado en La Araucanía de Chile, observamos que este es una práctica recurrente en el ámbito de la llamada defensa especializada, que se desarrolla progresivamente a partir de la década del 2000 , en vísperas de la adopción del modelo acusatorio de la reforma procesal penal (DPP, 2012). En este contexto, el peritaje antropológico, como cualquier otro tipo de peritaje, trasciende el estatus de auxiliar en la procuración de justicia y pasa a ser considerado como un instrumento de confianza; asimismo, deja de ser presentado solo como un informe escrito y se sitúa en el orden de la comunicación oral y la comparecencia directa (Duce, 2014).

De acuerdo con nuestra experiencia investigativa de campo y de gabinete, el peritaje antropológico puede conceptualizarse como un proceso compuesto por momentos, acciones y productos analíticamente discernibles. En primer lugar, se advierte un momento de diseño pericial en el que el/la perito es solicitado por el/la requirente, de modo que la/ el perito inicia un proceso de elaboración de un plan de indagación pericial. Muchas veces este momento es nebuloso y si no hay comunicación entre el perito y el requirente, puede conducir a acciones erráticas e ineficaces de ambas partes. Un segundo momento consiste en la producción de las pruebas periciales. Este momento es el más importante y en él se conjugan aspectos teórico-metodológicos, rela- cionales y circunstanciales respecto del objeto de investigación pericial, los que son plasmados en el informe antropológico para facilitar la comprensión y la formación de convicción jurídica. La investigación pericial en el ámbito penal enfrenta al antropólogo a tener que tratar asuntos ignorados muchas veces en la disciplina, ya sea por desinterés y pudor, o bien por etnocentrismo y respeto al canon académico. Un tercer momento del proceso corresponde al de la comunicación oral del producto de la investigación pericial. Este momento es muy similar al de una defensa académica de tesis, pues al igual que en esta, el tribunal no solo está atento a la exposición del perito sino que también será perspicaz con este y procurará someterlo al juego de la valoración crítica.

\section{Usos del peritaje antropológico}

Nuestra investigación sugiere que hay dos campos interrelacionados al respecto. El primero de ellos vincula los usos del peritaje antropológico a los objetivos en virtud de los cuales el/la requirente solicita su concurrencia. El segundo, en tanto, remite a las materias objeto de las pericias solicitadas y desarrolladas. Respecto de los usos en virtud de los objetivos, reconocemos usos procesales, cognoscitivos, comunicativos y ético-políticos. En Chile los usos procesales son los más practicados, pues responden al mandato institucional que deben observar las/los defensores penales públicos. En países como Perú (Hurtado, 2006), México (Villanueva, 2014) y Argentina (Kalinsky, 2001), el peritaje antropológico ha sido empleado desde los años noventa para eximir o reducir penas cuando es aplicado a imputados indígenas. Lo mismo ha 
ocurrido en Chile, en el marco de la Ley Indígena 19.253 de 1993, aunque su invocación ha sido tardía y circunscrita a la instalación de la DPM, en $2003^{4}$. A este objetivo procesal hay que agregar los de salida alternativa, acuerdo reparatorio, cautela de garantía, revisión y determinación de penas, en los cuales el peritaje antropológico también puede aportar. De este modo, el peritaje antropológico y el/la perito participan en acciones esenciales del proceso judicial, tales como la defensa, la decisión y la reparación.

Desde el punto de vista cognoscitivo, el peritaje antropológico es una práctica inscrita en los cruces entre la antropología aplicada y la antropología jurídica, orientada a generar prácticas antropológicas basadas en el conocimiento científico social sobre las diversas y desiguales formas de procurar justicia entre los distintos colectivos humanos. Siguiendo a Sánchez Botero (2010: 40), la antropología jurídica es una rama de las ciencias antropológicas que "puede intervenir igualmente realidades [socio] culturales al determinar estructuras cognitivas que podrían eliminarse o sustituirse para incorporar otros principios y otras reglas que respondan a ciertas demandas históricamente emplazadas". La función cognoscitiva del peritaje antropológico se torna necesaria en contextos de diversidad sociocultural en los que es preciso "considerar o descartar el contexto sociocultural del "criminal" o del "desviado" en el momento de juzgarlo y de aplicarle determinada norma externa" (Ídem: 27). De este modo, el peritaje antropológico es una herramienta útil para conocer aspectos desconocidos por los agentes jurídicos acerca de los modos como otros individuos y colectivos organizan y disponen sus ideas y acciones en cuanto a lo normal y lo desviado, ofreciendo insumos argumentales o propositivos para construir la prueba y visualizar líneas o estrategias del caso a partir de evidencia sociocultural. El peritaje antropológico da luces para comprender y/o explicar apropiadamente la lógica de las acciones humanas, al situarlas en las coordenadas socioculturales y temporo-espaciales de ocurrencia de las mismas. Para esto, el/la perito relativiza "como absolutas y universales las categorías de un solo derecho, como el positivo estatal, para tratar en cambio de entender otras categorías, a partir de las relaciones sociales propias de cada sociedad históricamente determinada" (Ídem: 39).

Un tercer modo de uso del peritaje antropológico concierne al que denominamos comunicativo, precisamente porque propende a ser un vehículo de diálogo entre actores cultural y políticamente distintos en los actuales contextos de pluralismo jurídico y justicia intercultural en los que emergen (Guevara Gil, 2015; Lachenal, 2015) y/o fortalecen en América Latina (Fabre, 2011; Sánchez Botero, 2010; Grijalva \& Exeni, 2012). El/la perito antropólogo/a brinda evidencias y enfoques teóricos para la argumentación y la formación del convencimiento del juez acerca de hechos que este ignora, pues forman parte de universos socioculturales ajenos o distintos al propio. La tarea consiste así en poner en los términos propios aquello que es comprendido en los términos de otros. Este proceso de traducción no es simple ni mecánico, pues los términos supuestamente propios pueden ser también ajenos o lejanos para el/la perito antropólogo/a. Para exponer el significado de los modos de pensar, sentir y actuar de la alteridad, el/la perito tiene que ser suficientemente hábil para conducir a que los agentes jurídicos "se miren a sí mismos como parte de una sociedad occidental tan exótica como cualquiera de 
las que se clasifican como indígenas" (Sánchez Botero, 2010: 327). Se trata de una práctica que precisa habilidades orientadas a la persuasión, a partir de modos sistemáticos y creativos de descripción y explicación.

La cuarta modalidad concierne a lo que llamamos uso de orientación ética-política. En este caso, el peritaje antropológico es parte de una estrategia de acción que busca superar fracturas ancladas al colonialismo y el monismo de los Estados unitarios y de aquellos que, asumiéndose pluralistas, aún se hayan ceñidos a esquemas formalistas heredados. En México hay informes periciales que avalan sentencias nacionales e internacionales que surten efectos contrahegemónicos (Lachenal, 2015). Otras autoras sostienen el principio de "la defensa de los indígenas por su condición de subordinación frente a los aparatos de justicia y ante la ley" (Valladares, 2009: 8), de manera de crear un nuevo trato entre el Estado nacional y los pueblos indígenas, en contextos de desigualdad (Fabre, 2011). Este uso del peritaje antropológico -y el anterior- se relaciona con una antropología aplicada al cambio en la cultura jurídica dominante. A juicio de Valladares (2012: 12), no solo se trata de promover prácticas de tolerancia sino de "relaciones interculturales basadas en el respeto y la equidad". En Colombia, Sánchez Botero (2010) se refiere al peritaje antropológico como una forma específica de poder que puede alterar las estructuras monolíticas del derecho estatal, al cuestionar el saber hegemónico, mediante el examen y la valoración de contenidos que no están dados por garantizados. A su juicio, el peritaje antropológico "logra generar un discurso alternativo que perturba y desmorona el dogmatismo jurídico" (Ibíd.: 134). Si el peritaje antropológico puede perturbar el orden dado, entonces su potencia- lidad estratégica es incontrovertible en el plano disciplinario y profesional.

En cuanto a las materias en las que se enfoca el peritaje antropológico, ellas son muy variables a nivel comparado y dependen, entre otros aspectos, del estatus político-jurídico en que se encuentran los distintos pueblos, naciones, comunidades y colectividades al interior de los Estados, los modos de relación entre ellos, las circunstancias históricas en que se encuentran y los aspectos socioculturales distintivos de cada colectividad. En general, las materias en las que se enfocan los peritajes antropológicos requeridos en el ámbito penal, corresponden a hechos y situaciones de conflicto que implican a indígenas rurales y urbanos, migrantes, miembros de grupos religiosos y de cultos, minorías sexuales y raciales, cuyas conductas y visiones de mundo están reñidas con las normas internas o endogrupales y con las propias del derecho estatal dominante. Abarca conflictos interpersonales, familiares, comunitarios, religiosos, territoriales y ambientales, actuales e históricos, sobre los que los agentes jurídicos requieren contar con elementos socioculturales, para su comprensión y valoración jurídica. Asimismo, concierne a las características socioculturales de las personas y/o grupos involucrados en situaciones penales, sus contextos de vida, las instituciones que encarnan y los procesos históricos y biográficos que los singularizan.

Cabe señalar que no se puede establecer una relación simétrica entre la casuística penal y la antropológica, por cuanto los tipos delictuales definidos desde el marco penal no tienen en cuenta el significado desde el cual la antropología busca comprender la conducta o el hecho pericial. Por ejemplo, lo que desde el marco penal puede ser concebido como un delito de 
porte y comercialización de estupefacientes, desde el marco antropológico representa una práctica asociada a la celebración de ritos festivos en los que la hoja de coca es un bien cultural altamente estimado que reactualiza los lazos sociales y religiosos de los participantes.

Una de las materias más tratadas por parte de los antropólogos/as en el ámbito penal latinoamericano corresponde a la costumbre indígena (IIDH, 2010; Verona, 2015; Lillo, 2010; Guevara Gil, 2015; Valladares, 2012). El concepto de costumbre remite a uno de los posibles marcos de comprensión disponibles en la antropología sociocultural para ofrecer una explicación juiciosa sobre asuntos que el juez o jueza ignora. El alcance de esta concepción acerca de la materia objeto del peritaje antropológico es evidente a todas luces: deja fuera fenómenos como el cambio, la resistencia, la resignificación y la innovación, y suprime posibles líneas de argumentación y prueba que el perito puede ofrecer a la defensa y al juez. El análisis de la casuística penal que ha contado con peritaje antropológico en La Araucanía, sugiere que además de acreditar la vigencia de costumbres, los peritajes antropológicos han servido para reconstruir contextos socioculturales y familiares de vida, demostrar afectación sociocultural al interior de grupos locales, ilustrar fenómenos socioculturales emergentes, acreditar identidad y/o pertenencia étnica-cultural y esclarecer significados de objetos, prácticas, roles e instituciones sociales diversas, tanto de personas indígenas como nacionales.

Por otro lado, la invocación de la costumbre por parte de los actores jurídicos está sujeta a usos estereotipados que no siempre tienen el efecto deseado si son tratados de manera irreflexiva. Cuando la costumbre sirve para eximir de responsabilidad penal, el perito adhiere sin querer a un uso colonial del derecho; por el contrario, cuando no hay evidencia suficiente para sostener la vigencia de la costumbre, el peritaje y, por ende, el perito, deviene innecesario. De acuerdo a nuestras indagaciones, esto se produce cuando no hay comunicación apropiada entre el/la perito y la defensa, y cuando el/ la perito satisface la solicitud de esta sin problematizar sus términos y alcances.

\section{El peritaje antropológico entre los actores jurídicos}

Tanto en Chile como en otros países de América Latina, el peritaje antropológico ha sido motivo de afirmación y rechazo por parte de los actores jurídicos del sistema estatal y, en menor medida, de los líderes de las organizaciones indígenas. Dentro de los primeros, quienes aceptan su uso en los casos penales, lo hacen ya sea por razones instrumentales o estrictamente procesales. Otros se sienten atraídos a participar en el proceso de cambio del paradigma jurídico, asumiendo un compromiso ético - político con el reconocimiento de la diversidad sociocultural. En este caso, estamos frente a una perspectiva en la que el peritaje antropológico es una herramienta necesaria para la afirmación de las diferencias socioculturales en el campo jurídico.

Por otro lado, quienes niegan la necesidad de contar con peritaje antropológico en el campo jurídico penal, lo hacen a partir de la afirmación de la supuesta unidad sociocultural de los colectivos que conforman su sociedad de pertenencia. Bajo esta perspectiva, los actores jurídicos pueden prescindir de las ramas sociocultural y jurídica de la antropología. De este 
modo, sustraen de manera a priori una condición existencial de la vida social y así todo el proceso jurídico es despojado de los contenidos que otorgan especificidad a los contextos efectivos de ofensa y defensa. Esta perspectiva es francamente ingenua y fácilmente criticable en el contexto de complejización del mundo de la era tardío-moderna en la que vivimos.

Otra de las razones por las cuales los actores jurídicos valoran o desestiman el peritaje antropológico en el ámbito penal, concierne a las nociones de ciencia que ellos asumen. Para Ávila Linzán (2011), el peritaje antropológico está condicionado por la cultura jurídica apegada al formalismo jurídico, es decir, a supuestos tales como la autorreferencialidad del derecho, la razonabilidad de la justicia, la objetividad, la practicidad y la predictibilidad. Dado que la antropología sociocultural no está anclada a estos mismos supuestos, el peritaje antropológico termina siendo la expresión de una pseudociencia. En Chile el peritaje antropológico ha sido cuestionado por jueces que consideran que la antropología no es una ciencia exacta y expresan desconfianza hacia sus métodos, datos y conclusiones (Lillo, 2010; DPP, 2012).

Por otro lado, la doctrina de la sana crítica, imperante en los códigos penales de la región, impone el requisito epistemológico de la consistencia interna como criterio de valoración de la prueba pericial. La antropología sociocultural, en tanto, exige romper dicho marco para comprender científicamente la alteridad, la cual abarca expresiones racionales y no racionales de la conducta humana (Shweder, 1992). En este sentido, el peritaje antropológico "adopta una forma particular de construir su propia objetividad, a partir de datos identificables no en su mensurabilidad, sino en su contenido de percepciones, interrelaciones y explicaciones estructurales" (Ávila Linzán, 2011: 24). No siempre esto es comprendido y algunos jueces piensan que las pruebas que ofrece el/la perito antropólogo/a son invenciones subjetivas, ideológicas o apologéticas. De acuerdo a nuestras indagaciones, en Chile y La Araucanía se advierten dosis similares de apertura y resistencia por parte de los jueces a valorar el uso de peritajes antropológicos en los casos en que sea necesario. Donde las diferencias son notorias es en el ámbito de las partes litigantes, entre las cuales, la de las/los defensores ha sido la más proclive a integrar el peritaje antropológico como parte de sus estrategias jurídicas.

Una última cuestión concierne al respeto epistemológico que los actores jurídicos tienen hacia ciertas disciplinas involucradas en los procesos judiciales. En nuestra experiencia como peritos antropólogos y analistas de los peritajes de otros colegas del sur de Chile, observamos una marcada presencia del peritaje psiquiátrico en casos en los que también concurre el peritaje antropológico. Al respecto, notamos que se produce un uso multidisciplinario de los peritajes por parte de la defensa. Observamos que en los casos penales en que las/los peritos de ambas disciplinas -psiquiatría y antropología sociocultural- han confluido, los jueces han valorado la prueba psiquiátrica por encima de la antropológica. Para entender esta relación, hay que considerar cuestiones como el momento histórico en que cada una de las pericias ingresa al campo penal como medio de prueba; el nivel de familiaridad que alcanzan los actores jurídicos con respecto a los lenguajes y racionalidades específicas de cada una de las disciplinas implicadas; y, en esta última línea, hay que atender a la pertinencia y necesidad 
de cada una de las pericias de acuerdo con la especificidad de sus objetos y campos de conocimiento y aplicación.

\section{El peritaje antropológico en la defensa penal de La Araucanía}

Entre fines del 2003 y principios del 2014, se realizaron en La Araucanía un total de 63 peritajes antropológicos en casos penales de distinta índole. En esta oportunidad hemos dejado fuera los peritajes realizados entre los años 2000 y 2003, por no contar con información digitalizada. Un análisis posterior podría incluir los peritajes realizados en otras regiones del país, en las que los peritajes conciernen a indígenas, migrantes y campesinos ${ }^{5}$.

Al observar el gráfico de peritajes antropológicos realizados no se observa una tendencia clara. Entre los años 2004 y 2009 hay una disminución paulatina de solicitudes de peritajes. De hecho, en los años 2008 y 2009 solo se solicita un peritaje por año, a diferencia del año 2004 que se solicitaron 11 peritajes. En los años 2011 y 2012 reaparecen las solicitudes, alcanzando 10 y 9 pericias, respectivamente. El 2013 desciende nuevamente el número de pericias solicitadas. Así, el panorama longitudinal es oscilatorio e impredecible. La propia experiencia de los autores de este artículo señala que en el último tiempo hay una mayor preocupación de los defensores por incorporar el peritaje antropológico como prueba judicial, lo que es avalado también por una mayor consideración de los jueces respecto a los argumentos antropológicos declarados en juicios orales. Frente a la tesis de la subutilización de los mismos en los juicios orales (Álvarez, 2014), nos preguntamos si estará o no cambiando la visión de los jueces respecto al valor asignado a la prueba pericial antropológica.

\section{Gráfico $\mathbf{N}^{\circ} 1$}

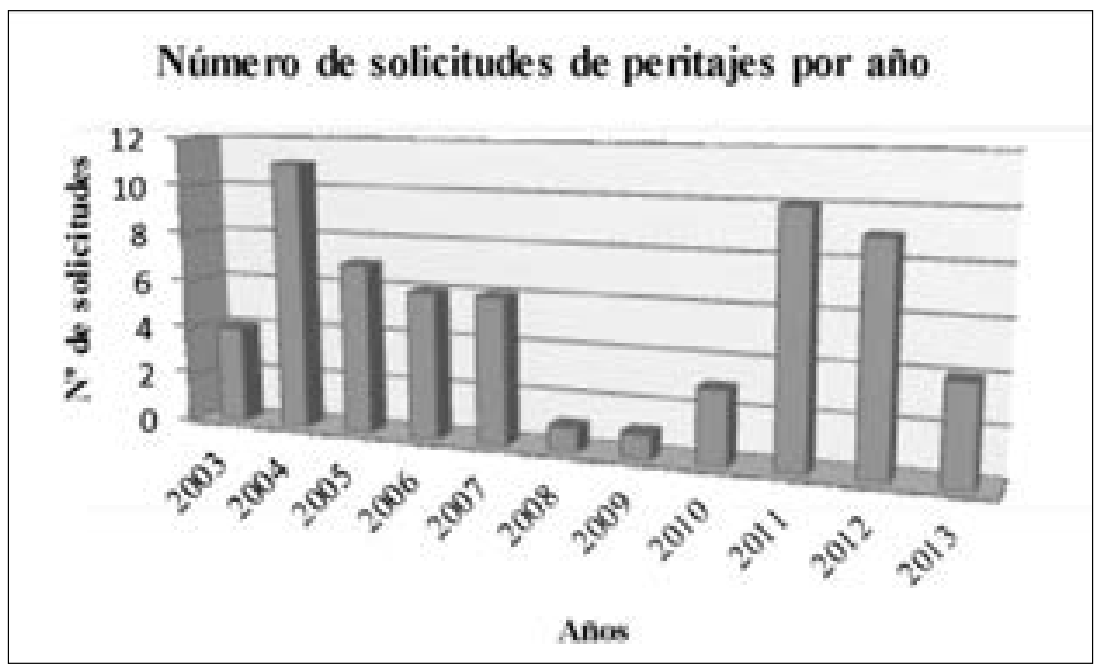

Fuente: Elaboración propia 
Además de las/los abogados defensores de la DPP que solicitan peritajes antropológicos en el contexto de indagación, encontramos solicitudes de defensores privados y de ONG, asociados en su mayoría al conflicto interétnico regional ${ }^{6}$.

\section{Características de las causas asociadas a peritaje antropológico}

De los 44 casos analizados, 18 de estos, es decir, un $40 \%$ corresponden a causas de violencia intrafamiliar (VIF), predominando el maltrato habitual, el abuso sexual, la violación entre parientes y, en menor medida, el infanticidio, el parricidio y el femicidio. Del total de casos asociados a VIF, uno corresponde a una imputada no mapuche acusada de infanticidio. Una mirada acuciosa desde la perspectiva sociocultural a algunas de estas causas puede mostrar que no hubo delito o que el delito se realizó motivado por ciertos contextos culturales, como en el caso que se presenta más adelante. Asimismo, puede revelar que, dentro del ordenamiento jurídico indígena, ciertos "delitos" podrían ser tratados evitando penas carcelarias, cuando la situación lo amerite.

En segundo lugar, los casos más recurrentes están asociados al conflicto interétnico chileno - mapuche ${ }^{7}$, con un total de 12 casos que representan un $27 \%$ de las causas a las que concurre el peritaje antropológico. Por lo general, estas causas comprometen a más de un imputado, ya que el conflicto concierne a un problema colectivo que tiene raíces históricas. Se trata de causas complejas, en las que los juicios son largos y cuentan con una notoria difusión mediática. Se ha llegado a contabilizar hasta once imputados, donde la defensa ha estado patrocinada por la DPM, defensa privada u ONG. Algunos de estos delitos son caratulados como asociación ilícita terrorista, atentados contra la propiedad y las personas, tenencia ilegal de armas de fuego, amenazas, entre otros. Los peritajes asociados a estas causas apuntan a explicitar las condiciones de vida de los imputados y sus comunidades de pertenencia, así como a reconstruir la organización social de las instituciones tradicionales de sus líderes.

En tercer lugar figuran los peritajes antropológicos asociados a homicidios, habiendo seis casos, equivalentes al $14 \%$ del total. El peritaje es usado en estas causas para describir el contexto sociocultural del imputado y las relaciones y significados que motivaron su actuar. No obstante, la teoría del caso se elabora bajo el supuesto de que los imputados tienen problemas psíquicos o mentales, invocando en el Artículo 10 № 9 del Código Procesal Penal, defendiendo la tesis de que en estos casos la persona habría actuado inducida por una "fuerza psíquica irresistible" y un "miedo insuperable". Como mostraremos, en estos casos la explicación socio-antropológica es sustituida por la explicación psíquica.

Asimismo, ha habido tres casos $(7 \%$ del total) asociados a conflictos entre miembros de comunidades mapuche, derivados del actual conflicto con la sociedad chilena, las empresas forestales y el Estado. En estos casos el peritaje antropológico apunta a determinar la calidad de lonko de la víctima, a fin de evitar la agravante que busca afirmar la fiscalía, argumentando que el defendido es una víctima y una autoridad tradicional. En los otros casos, el peritaje antropológico determina las relaciones conflictivas de las comunidades como parte de las dinámicas propias de las relaciones internas. 


\section{Gráfico $N^{\circ} 2$}

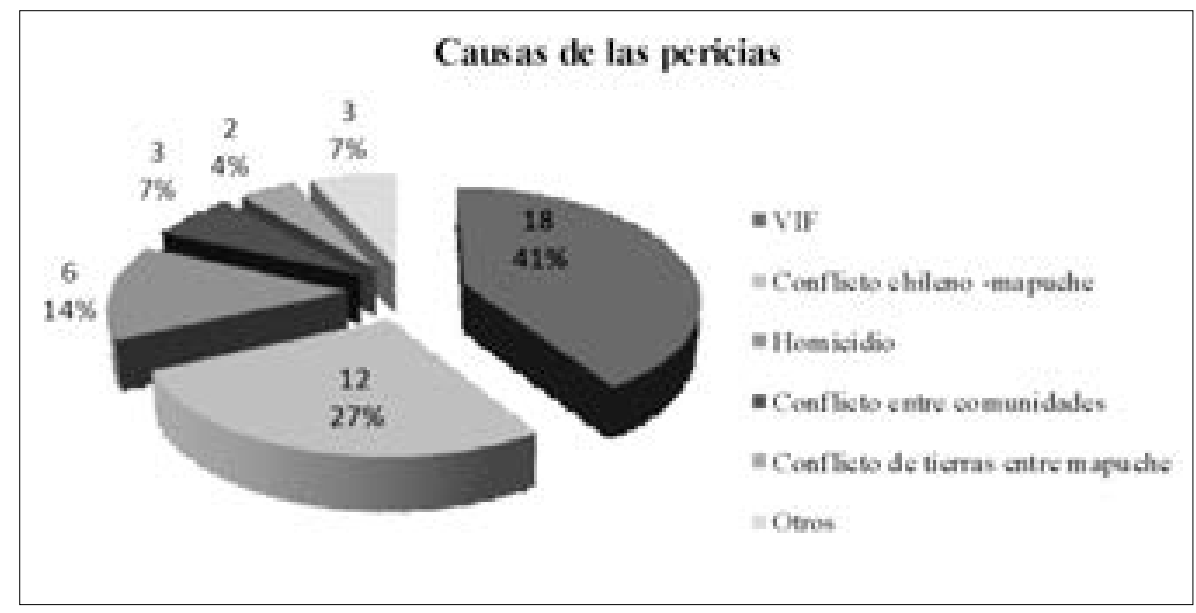

Fuente: Elaboración propia

Los delitos para los cuales se ha solicitado peritaje antropológico son en su mayoría (48\%) del tipo intraétnicos, es decir, relacionados con conflictos internos de la sociedad mapuche. Siguiendo en importancia numérica, encontramos los delitos asociados a conflictos interétnicos, que alcanzan un $45 \%$ de las causas analizadas. A diferencia de lo que ocurre en países como Colombia, Perú o Ecuador, no se registran casos en que se busque afirmar el derecho propio o la libre determinación jurídica del colectivo afectado.

Respecto a peritajes realizados sobre causas no indígenas, se registran tres casos $(7 \%$ del total), asociados a los delitos de femicidio, robo con violencia e infanticidio. En dos de estas causas el imputado es mujer, mientras que en la causa de femicidio el autor es un hombre. En estos peritajes llaman la atención respecto de las nociones prevalecientes acerca del campo de aplicación de la antropología en el campo penal, al sugerir que ellos pueden concurrir en casos no indígenas. Un desafío es superar este esquema prevaleciente y abrir el campo del peritaje antropológico a otras causas asociadas, por ejemplo, a población migrante, grupos vulnerables de la sociedad chilena, racismo, relaciones de género, violación a derechos humanos, libertad de culto, etc.

\section{Características de los imputados y víctimas en los casos penales con peritaje antropológico}

\section{Respecto de los imputados}

Hay un total de 69 imputados asociados a las 44 causas analizadas. La mayor parte proviene de comunidades mapuche de las comunas de Ercilla, Collipulli y Padre Las Casas. Le siguen Temuco, Carahue, Traiguén y Chol Chol. Seguramente el hecho que el 2016 se haya abierto una DPM en Imperial y Collipulli traerá como consecuencia el aumento de casos en estas comunas y en las comunas vecinas a estas.

Un $83 \%$ de estos imputados corresponde a hombres mapuche y un $11 \%$ a mujeres mapuche. Mientras que un $6 \%$ corresponde a imputados e imputadas no mapuche, distribuidos 
de manera equitativa. Al revisar en detalle la condición étnica, el sexo de los imputados y los delitos impugnados, tenemos que la mayor parte de los hombres se asocian al conflicto chileno - mapuche, conflictos entre comunidades, delitos violentos como homicidio y VIF en todas sus formas, incluyendo el abuso sexual, el femicidio y todo tipo de agresiones. En el caso de las mujeres, llama la atención que los delitos están asociados a conflictos familiares asociados a condiciones de exclusión y marginalidad. Es el caso de incestos practicados por personas mapuche y no mapuche, parricidio de una mujer que asesina a su marido luego de años de maltrato y racismo, habiendo una doble discriminación por sexo y etnia.

En el caso de imputados no mapuche hay un delito de femicidio y en el otro el imputado habría participado en agresiones en un contexto de conflicto entre comunidades mapuche. En el caso de los delitos perpetrados por mujeres no mapuche, los dos delitos descritos corresponden a infanticidio y robo con violencia, en contextos de marginalidad social urbana.

Otro dato relevante es que, de los 69 imputados, siete corresponden a autoridades tradicionales mapuche -lonko y machi-, es decir, un $7 \%$ del total analizado. La mayor parte de los delitos en estos casos están asociados a situaciones de conflicto interétnico donde se imputa y absuelve. Es el caso de los lonko Pascual Pichun y Aniceto Norin, condenados y posteriormente absueltos por asociación ilícita terrorista.

\section{Respecto de las víctimas}

En las causas analizadas se advierte un 55\% de víctimas no mapuche versus un $45 \%$ de mapuche. En el primer caso, se trata de víctimas ligados a conflictos interétnicos, mientras que las causas con víctimas mapuche se relacionan a conflictos intraétnicos, asociados a fenómenos de marginalidad y exclusión social, cultural y racial. En estas causas el peritaje antropológico incorpora antecedentes históricos, biográficos y culturales que contextualizan las conductas, evitando referencias a ellas como delitos.

\section{Condiciones del proceso pericial}

Un tema importante en el proceso pericial antropológico es el de los plazos que determina la DPP para su realización. En tanto medio de prueba jurídica, llama la atención que los peritajes antropológicos se soliciten al finalizar los plazos para la presentación de pruebas. En los 44 casos revisados los plazos otorgados para la elaboración de los informes va desde uno a veintiocho días. En un $46 \%$ de los casos, la DPP solicitó los informes en un plazo que iba desde los ocho a los catorce días; en un 35\% de los casos desde los quince a los veintiocho días; $y$, en un $19 \%$ de los casos entre uno y ocho días. Es relevante considerar tiempos suficientes para elaborar informes de este tipo, ya que en su mayoría requieren acercamientos de campo, visitas a los centros penitenciarios, entrevistas con personas vinculadas al imputado $y$, en general, trabajo de gabinete para elaborar aspectos teóricos y empíricos, sobre todo en materias ignoradas en la disciplina. Más allá de este hecho, los plazos que impone la DPP para realizar informes periciales antropológicos afectan aspectos como la rigurosidad, la representatividad y la validez científica de los resultados.

Otra de las condiciones bajo las cuales actualmente se realizan los peritajes antropológicos para la defensa penal en Chile, concierne al contexto socio-jurídico en el que estos se 
efectúan. Particularmente, los peritajes asociados a causas interétnicas se despliegan en una atmósfera compleja, tensionada por posiciones y visiones sociales antagónicas, en las que simultáneamente se afirma y niega la responsabilidad del imputado. En casos de alta connotación pública mediática, la primera de estas posiciones suele tener mayor influencia social que la segunda. La condena al machi acusado del crimen del matrimonio de ancianos Luchsinger-McKay, ocurrido en enero de 2013, generó la visión del imputado como la de un monstruo que bajo ninguna circunstancia merecía la indulgencia. Mientras uno de nosotros realizaba la pericia orientada a obtener cautela de garantía, él ya era visto como un condenado, sobre el cual se dudaba de su autenticidad e integridad mapuche y de machi. En el terreno jurídico, la diversidad sociocultural sirve como una estrategia de defensa, a la vez que como un símbolo de lo indeseable que, por su sola existencia, socava la oportunidad de convivir en armonía con las diferencias humanas.

\section{Evaluación del peritaje antropológico}

Los informes periciales son evaluados por la Unidad de Estudios de la DPP. Al observar dicha evaluación nos arroja un promedio de un 6,6 en relación a los informes periciales estudiados. Los rangos de evaluación van desde una nota 4,2 a un 7,0 .

Según disposiciones institucionales, el/la defensor/a evalúa el informe según dos criterios: por un lado, al tiempo de respuesta del perito ante la solicitud del defensor y, por otro lado, la calidad de la presentación del perito en el juicio oral. Mientras el tiempo es un criterio que atraviesa todo el proceso judicial, el último hecho es constitutivo del esquema adversarial que introduce la reforma procesal penal. Según este esquema, se espera que las partes expresen sus pruebas, tesis y argumentaciones en la instancia consagrada para ello. De allí que el defensor se siente complacido con el perito una vez que este ha prestado declaración en el juicio, antes que con la entrega del informe pericial.

Respecto de la evaluación del desempeño del perito en el juicio oral, no contamos con registros cuantitativos que permitan visualizar más claramente la opinión de las/los defensores. Según el marco institucional vigente, la evaluación se realiza conforme a los siguientes criterios: comparecencia adecuada, adecuada con reparos y no adecuada. El marco institucional no ofrece una definición explícita de la adecuación como criterio de valoración de este desempeño, a pesar de su importancia. Sí señala que el fin de la comparecencia del/la perito en el juicio oral es "exponer el contenido y conclusiones del informe entregado y bajo las condiciones que establezca la Defensoría" (DPP, 2014: 28). La adecuación supondría entonces actuar conforme a este fin institucional.

En otro documento de la institución, proporcionado por la ex jefa de la Unidad de Estudios de la DPP de La Araucanía, se ofrece mayor claridad acerca de los criterios de evaluación de la conducta del perito durante el juicio oral. Según el documento, la evaluación concierne a "la defensa del informe por el perito en el juicio oral", considerando los siguientes "factores":

- "Claridad, sencillez y seguridad en la exposición del contenido y conclusiones del peritaje durante el interrogatorio $y$ contrainterrogatorio. 
- Coherencia entre las declaraciones del perito y los contenidos del informe.

- Capacidad del perito de generar convicción acerca de su competencia como testigo experto (exposición de su experticia, estudios, experiencia profesional en su especialidad, etc.).

- Relevancia del resultado del peritaje para el objetivo procesal buscado (sentencia absolutoria o condenatoria con rebaja de pena, beneficios alternativos, etc.)."

Estos criterios van más allá de la adecuación lógica. Cada uno de los llamados "factores" representa una dimensión particular del rol del perito en el comparendo. En el mismo orden en que se presentan los factores, la evaluación concierne a la faceta expresiva, la lógica, la persuasiva y la procesal.

\section{Casos relevantes:}

\section{peritajes antropológicos a prueba}

El Ministerio Público contra V.L.M. (2004) cuando el peritaje antropológico se vuelve en contra de la teoría del caso.

V.L.M., agricultor mapuche de 66 años de un sector rural de la comuna de Galvarino, fue acusado de haber abusado sexualmente de su sobrina nieta entre 2003 y 2005, abusos que terminaron con el embarazo de la joven a los 13 años de edad. El defensor público licitado solicitó en agosto de 2004 un peritaje antropológico con el fin de apoyar "la tesis de conducta influenciada por factores culturales", según indica el informe pericial realizado. La solicitud formal, en tanto, se realizó considerando la identificación del imputado como mapuche, a partir de la cual la defensa supuso que podría "legitimar la conducta" sexual del imputado. La defensa también incluyó un peritaje psicológico, en el que se atribuyó "desorden orgánico cerebral" inherente a la edad de la persona y "posible trastorno de personalidad asociado al control de impulsos". El antropólogo se enfocó en relevar rasgos de la familia mapuche, la edad de casamiento, las normas de parentesco y el rol de los abuelos, dejando de lado la calidad indígena del imputado y su relación con la cultura mapuche.

Las conclusiones del informe pericial establecen la posibilidad de que un hombre mapuche tenga relaciones sexuales con una mujer menor de edad, pero considera que el imputado "trastoca la costumbre cultural mapuche del cual es depositario, con impulsos sexuales no controlados". Si bien el perito antropólogo atestiguó en el juicio oral, la sentencia retomó textualmente varios de los elementos mencionados de las conclusiones de la pericia con el fin de asentar un veredicto condenatorio. El informe del antropólogo es citado para indicar que el imputado y la víctima pertenecen a la "etnia mapuche donde las relaciones sexuales representan un problema cultural", o también por enfatizar la importancia de los mayores en dicha cultura, aspecto que podría explicar que la joven se haya inhibido ante los abusos de los cuales era víctima de parte de su tío abuelo.

En definitiva, la pericia antropológica permitió asentar la culpabilidad del imputado sin poder aportar mayor explicación de orden sociocultural a su actitud. La falta de claridad en la fundamentación de la solicitud y de sus términos llevó al perito a elaborar una pericia que no respondía, e incluso se contraponía, a la teoría del caso, provocando sospechas acerca de su necesidad en el proceso. 


\section{El Ministerio Público contra M.M.Q. (2013) ${ }^{10}$ : reconocimiento parcial de la pericia antropológica.}

Este es un caso de femicidio ocurrido en el transcurso del mes de julio de 2012, en una comunidad mapuche cercana a Temuco, donde M.M.Q. agredió con un cuchillo a su esposa, dándole muerte. La defensora penal mapuche invocó, durante la fase de preparación del juicio oral, la teoría según la cual el imputado padecía de una enfermedad mapuche -mapuche kutran- que le había provocado la pérdida de consciencia al momento de cometer el delito. En este contexto la defensora solicitó, en noviembre de 2012, una pericia antropológica a partir de la autoidentificación y adscripción del imputado a los valores y cosmovisión mapuche, su participación en las ceremonias y actividades de la comunidad, y la supuesta existencia de un "mal", bajo cuya influencia se encontraba el imputado y que sería el origen del ilícito cometido. Se requirió entonces corroborar dichos antecedentes desde una perspectiva antropológica y "cosmovisional".

La solicitud fue aprobada y se designó a un perito antropólogo con carácter urgente para que elaborara su informe en un plazo de diez días. El informe resultante se basó en una revisión de los antecedentes disponibles en la carpeta investigativa del imputado -proporcionada por la DPM-, una entrevista realizada a este en el Centro Penitenciario de Temuco, y entrevistas a dos machi que habían atendido sus padecimientos. El informe indica que "todo lo anterior se complementó con [la] revisión y análisis de material teórico relacionado con la conceptualización de la enfermedad y el sistema de salud en el mundo mapuche".
La pericia antropológica sirvió como medio de prueba en el juicio oral realizado en el TOP de Temuco en agosto de 2013, para sustentar la teoría del caso de la defensa, según la cual la enfermedad mapuche sería un eximente, apelando para ello al artículo 10, 9 del Código Penal y al artículo 54 de la Ley Indígena, solicitando la absolución del imputado. Para robustecer su teoría, además de la exposición del perito antropólogo, la defensa recurrió al testimonio de uno de los machi que vio al imputado al inicio del proceso llevado en su contra en el Hospital Intercultural de Nueva Imperial. La fiscalía incluyó peritaje psiquiátrico, el que atribuyó al imputado alcoholismo crónico y sospechó de la certeza de las aseveraciones de este acerca del "mal" que afirmaba le habían hecho.

El 17 de agosto del año 2013 se dictó sentencia condenatoria en contra de M.M.Q. imponiéndosele la pena de 10 años y 1 día de presidio mayor en su grado medio, dando por acreditada la participación del acusado en el femicidio. El tribunal valoró la pericia antropológica al aceptar la enfermedad mapuche como una causa que afectaba la conducta del imputado. Sin embargo estipuló que

\footnotetext{
"el acusado M.M.Q. no se encuentra amparado por la eximente del artículo 11 № 1 en relación con el artículo 10 № 1 del Código Penal menos aún en la hipótesis del artículo 10 № 1, puesto que él, al dar muerte a su mujer estaba en pleno conocimiento de que cometía un delito; que si bien se encontraba afectado por dos tipos de enfermedades mapuches, ellas se encontraban relacionadas con su alcoholismo, puesto que se trata de enfermedades que se provocan cuando ellos trasgreden ciertas normas culturales (en este caso, precisamente la ingesta excesiva de alcohol); que, aun cuando se trata de una persona perteneciente a la etnia mapuche, que habla su lengua y practica los ritos de su religión; no es menos cierto que, de acuerdo al testimonio de todos quienes lo entrevistaron, así
} 
como del propio testigo de la defensa, don Eduardo Aguilera, señalaron que el acusado hablaba perfectamente el idioma español y que una semana antes, habían compartido un asado y que se encontraba bien, lo que concuerda con el hecho de haber trabajado por más de veinte años como arriero de una feria de animales y con el hecho de que en forma diaria venía a la ciudad de Temuco a vender leña, actividades que necesariamente le exigían comunicarse en español sin que nadie diera cuenta de que lo hacía con dificultad. De hecho, su propia hija Carolina señaló que ambos se comunicaban en este último idioma toda vez que ella no habla mapudungun".

En estas consideraciones se visualizan varios elementos significativos desde el punto de vista antropológico. Primero, los jueces reconocen la alteridad cultural expresada en el dominio de la enfermedad. Asimismo, atribuyen el origen de esta al alcoholismo en vez que, a la etiología propiamente mapuche, expuesta por el machi y el antropólogo en el juicio. Por otro lado, cuestionan la identidad mapuche del imputado en virtud del uso del castellano y de su participación en contextos de sociabilidad no mapuche. Lo que atraviesa este juzgamiento reposa sobre una división idealizada del mundo indígena por parte de los jueces, quienes distinguirían entre "indígena asimilado" y "no asimilado" (Modolell, 2006). Lo relevante es que el tribunal ha sido un escenario de representación de la identidad y la cultura mapuche, resultando la participación de un machi como testigo y de un antropólogo como perito, llevando a un reconocimiento, de parte de los jueces, de la existencia de una enfermedad mapuche, sin que ello implique un aceptación de la teoría del caso elaborada por la defensa.

\section{Conclusión}

Tras 16 años desde su instalación en la justicia penal chilena, el modelo acusatorio ha propi- ciado la incorporación de antropólogos como expertos que inciden en el desarrollo de prácticas que relevan las diferencias socioculturales en la procuración de justicia. Este proceso ha sido complejo debido a la ausencia de marcos y herramientas objetivas de valoración del peritaje antropológico en principio como prueba jurídica por parte de los actores jurídicos -especialmente de las/los jueces. El peritaje antropológico en el contexto latinoamericano y chileno aparece hoy como una prueba jurídica necesaria para un debido proceso de personas y grupos que han sido procesados en diversas causas. El informe de expertos en esta área del conocimiento permite aportar pruebas para acreditar la diferencia, la diversidad cultural y la alteridad.

Además que como una prueba, el peritaje antropológico es relevante para la defensa penal si se incorpora como forma de investigación y conocimiento que aporta datos de los contextos socioculturales e históricos. Es decir, que pueden ser cruciales para la construcción y justificación de las teorías del caso o porque ayudan a visualizar insospechadas líneas o estrategias de defensa a partir de evidencia sociocultural. Este potencial aún no ha sido expuesto y nos encontramos empeñados a hacerlo.

Si bien el peritaje antropológico se ha enfocado principalmente en causas donde el o los imputados son indígenas, se advierte que las causas no indígenas irán en aumento por las propias condiciones actuales de las migraciones y de los conflictos interétnicos, además de la diversidad de religiones y expresiones de género e identidad sexual, que pueden contravenir las normativas estatales. Ante la variedad de usos y potencialidades que tiene el peritaje antropológico a nivel comparado, en Chile su uso es aún incipiente. Este tiende a ser instru- 
mental a los objetivos procesales y en él sobresalen las referencias a la costumbre indígena como un comodín que, si bien permite el acceso y reconocimiento de la diversidad sociocultural como un hecho de la realidad, representa una camisa de fuerza epistemológica tanto para las/ los antropólogos como para los juristas.

Muchas veces el peritaje antropológico procede en situaciones de vida o muerte. De allí que sea un dispositivo controvertido para los involucrados, especialmente para las/los inculpados, víctimas y sus respectivas redes sociales, pero no por ello prescindible o sustituible. Cuando esta herramienta no es incorporada en situaciones meritorias, se pasa por alto un derecho incontestable y el proceso de justicia se ve fragilizado. Es preciso, en este sentido, asegurar un espacio ya conquistado en otros contextos latinoamericanos, de manera de avanzar hacia una justicia cada vez más pertinente y edificante.

Cuando el peritaje antropológico es usado junto con otros medios de prueba enfocados también en la comprensión de los asuntos humanos -como la psiquiatría, el trabajo social y la psicología-, puede conducir a efectos contraproducentes desde el punto de vista de la argumentación y la valoración jurídica de las pruebas. Hay que recordar que la valoración de las pruebas está fundada en los marcos de comprensión de miembros de la sociedad dominante, quienes pueden proyectar interpretaciones no controladas en sus decisiones. Así, de no mediar un método interdisciplinario de trabajo que encadene apropiadamente cada una de las pruebas que aportan los expertos y testigos, la prueba antropológica quedará sujeta a la deferencia y la familiaridad epistemológica que afirman las/los jueces hacia conocimientos no siempre aptos para comprender la alteridad.

El predominio del tratamiento estatal de las causas penales en las que participan las/los peritos antropólogos en Chile, lleva a que el peritaje antropológico se realice en contextos en que se reproduce el estilo de relaciones interétnicas asimétricas en el que los miembros de la sociedad, dividida en secciones opuestas, asumen diferentes compromisos con la justicia, a partir de posiciones y visiones controvertidas respecto de la diversidad sociocultural. Aun así, es posible iluminar este contexto, provocando la reflexión sobre el lugar que tiene la diversidad sociocultural en el orden jurídico estatal y propiciando medidas que afirmen el derecho propio y la libre determinación de los pueblos. Llegará el día en que sean estos, con sus propias autoridades, instituciones y mecanismos, los que se encarguen de administrar justicia entre sus miembros. Mientras tanto, la presencia de antropólogos/as en los tribunales seguirá siendo una realidad necesaria y deseada.- 


\section{Notas}

${ }^{1}$ Reforma que comienza en La Araucanía y Coquimbo el año 2000 y que modifica el sistema de procedimientos jurídico-penales del Estado chileno, pasando de un sistema inquisitorio a otro acusatorio, en el cual se separa las funciones de investigar, procesar y dictar sentencias. Los juicios son orales e inmediatos y se crea una Defensoría Penal Pública gratuita y un Ministerio Público -Fiscalíaencargado de investigar y formalizar los delitos.

${ }^{2}$ En ambos casos el peritaje antropológico lo realizó el antropólogo, médico y filósofo Alejandro Lipschutz de origen judío-letón. La primera causa asociada a un caso de parricidio y ajusticiamiento por brujería y el segundo caso asociado a una ceremonia compleja donde se sacrifica un niño en el contexto del maremoto de 1960.

${ }^{3}$ Se trata del proyecto Fondef IDeA ID14I10379 "Peritaje antropológico para la defensa penal en contextos de diversidad cultural", el cual es desarrollado por un equipo compuesto por antropólogos, abogado, trabajadora social, tesistas y practicantes de antropología y derecho, quienes trabajan de forma mancomunada con abogados de la DPP y DPM de La Araucanía, y de la Unidad de Estudios y Defensas Especializadas de la DPP nacional.

${ }^{4}$ De acuerdo al artículo 54 de esta Ley, se establece que "la costumbre hecha valer en juicio entre indígenas pertenecientes a una misma etnia, constituirá derecho, siempre que no sea incompatible con la Constitución Política de la República. En lo penal se la considerará cuando ello pudiere servir como antecedente para la aplicación de una eximente o atenuante de responsabilidad" (cursivas nuestras).

\section{Referencias bibliográficas}

Álvarez San Martín, R. (2014). "El peritaje antropológico y la defensa penal de imputados indígenas en la Araucanía, 2004-2011". CUHSO, Vol. 24 (1): 81-103.

Ávila Linzán, L. (2011). "Barreras ideológicas para la valoración judicial de los peritajes antropológicos”. Crítica Jurídica 31: 15 - 37.

Defensoría Penal Pública (2014). Resolución exenta 399. Establece nuevo sistema de peritajes en la DPP, y deja sin efecto Ordinario $N^{\circ} 214$ de fecha 13 de septiembre de 2005. Santiago: República de Chile, Ministerio de Justicia.

(2012). Modelo de defensa penal indígena. Documentos

Oficiales № 7, octubre. Santiago: Centro de Documentación Defensoría Penal Pública.

De Sousa Santos, B. (2011). "Epistemologías del Sur". Utopía y Praxis Latinoamericana 16 (54), Julio-septiembre, 17-39.

Duce, M. (2014). La prueba pericial. Buenos Aires: Ediciones Didot.

Fabre Zarandona, A. (2011). "Balances y perspectivas del peritaje antropológico: Reconocer o borrar la diferencia cultural”. Revista Pueblos y fronteras digital, 6 (11): 149-188.
${ }^{5}$ Es el caso de diversos peritajes de porte y uso de armas de fuego y uso de drogas para fines rituales; entre otros. Realizados en contextos rurales e indígenas en las regiones I, II, VII y XIV, por los antropólogos Francisca Fernández, Cristina Garrido, Paulo Castro y CONADI. En estos peritajes se aborda la tradición rural en el uso de armas de fuego para caza, protección del predio, animales y control de fauna silvestre que afecta los cultivos agrícolas. Además del uso histórico y ceremonial de la hoja de coca que, en los contextos periciados está lejos de ser un elemento ilícito, destinado al contrabando o a alterar el orden público.

${ }^{6}$ Es relevante considerar además de la DPP, la participación en la defensa de imputados mapuche que han tenido instituciones como el Centro de Investigación y Defensa del Sur (CIDSUR), la Comunidad de Historia Mapuche y la Fundación Instituto Indígena (FII) del Obispado de Temuco, además de abogados particulares.

${ }^{7}$ Nos referimos a casos en los cuales las diferencias étnico-culturales de los actores son motivo de disputas y tensiones normativas, políticas y culturales que afectan la convivencia social y los respectivos bienes jurídicos de las partes.

${ }^{8}$ RUC 03000956148-6; RIT 85-2004, Tribunal Oral en lo Penal de Temuco.

${ }^{9}$ Información solicitud de peritaje № 5925, DPP La Araucanía, 03-08-2004.

${ }^{10}$ RUC 1200689988-7; RIT 107-2013, Tribunal Oral en lo Penal de Temuco.

Garza, M. R. (2014). "Demuestre su atraso cultural: dos peritajes antropológicos de habitantes de pueblos originarios en contextos urbanos". Diario de Campo 4-5: $33-41$.

Grijalba, A. \& Exeni, J. L. (2012). "Coordinación entre justicias, ese desafío". En De Sousa Santos, B. y Grijalba, A. (Eds.) Justicia indígena, plurinacionalidad e interculturalidad en Ecuador, Quito: Abya Yala, Fundación Rosa Luxemburg.

Guevara Gil, A. (2015). "El peritaje antropológico en la Corte Superior de Justicia de Loreto". En Guevara Gil A., Verona A. \& Vergara R. (Eds.) El peritaje antropológico. Entre la reflexión y la práctica, Lima: Centro de Investigación, Capacitación y Asesoría Jurídica del Departamento Académico de Derecho (CICAJ).

Hurtado Pozo, J. (2008). "Derecho penal y diferencias culturales: el caso peruano". Disponible en: https://dialnet.unirioja.es/descarga/ articulo/4264638.pdf Fecha de consulta: 16 de junio de 2016.

Instituto Interamericano de Derechos Humanos (Ed.) (2010). Acceso a la justicia de los pueblos indígenas: los peritajes culturales y la visión de pobreza desde su cosmovisión, San José: IIDH, Agencia 
Sueca de Cooperación Internacional para el Desarrollo (Asdi), Agencia Danesa de Cooperación Internacional, Real Ministerio de Asuntos Exteriores de Noruega, Red de Atención a Pueblos Indígenas (RAPI).

Kalinsky, B. (2001). "La pericia antropológica como herramienta de investigación social". Revista de Antropología Iberoamericana, ㄲo 25.

Kalinsky, B. \& Cañete, O. (s/f). "La pericia antropológica como prueba judicial. El caso de la justicia penal". Centro Regional de Estudios Interdisciplinarios sobre el Delito, Argentina.

Lachenal, C. (2015). "Las periciales antropológicas en México: reflexiones sobre sus posibilidades y límites para la justicia plural”. En Guevara Gil A., Verona A. \& Vergara R. (Eds.) El peritaje antropológico. Entre la reflexión y la práctica, Lima: Centro de Investigación, Capacitación y Asesoría Jurídica del Departamento Académico de Derecho (CICAJ).

Lillo, R. (2010). "El Convenio 169 de la OIT y la defensa penal de indígenas". Defensorías Regionales. Minuta Regiona/ № 1, abril. Disponible en: http://www.dpp.cl/resources/upload/093e523d3fa9fe3d8745793ada63a58b.pdf Fecha de consulta: 8 de junio de 2016.

Modolell, J.L. (2006). "Breves consideraciones sobre la posible responsabilidad penal de sujetos pertenecientes a grupos culturalmente diferenciados (casos del indígena y costumbres de origen afroamericano)". Derecho Penal y Pluralidad Cultural, Anuario de Derecho Penal, 273-286.

Rodríguez, N. (2012). "Peritaje antropológico en Chile". Disponible en: http://es.scribd.com/doc/94351684/Peritaje-antropologico\#scribd. Fecha de consulta: 14 de agosto de 2015.

Sánchez Botero, E. (2010). El peritaje antropológico. Justicia en clave cultural. Bogotá: Deutsche Gesellschaft für. Cooperación

\section{Técnica Alemana.}

Shweder, R. (1992). "La rebelión romántica de la antropología contra el iluminismo o el pensamiento es más que razón y evidencia". En Geertz, C. (comp.) El surgimiento de la antropología posmoderna, Barcelona: Gedisa.

Taruffo, M. (2008). La prueba. Madrid: Marcial Pons. Ediciones Jurídicas y Sociales, S.A.

Valladares, L. (2009). "El peritaje antropológico: Los retos del entendimiento intercultural". Disponible en: http://sgpwe.izt.uam.mx/ files/users/uami/lauv/El_peritaje_antropologico._Los_retos_del_entendimiento_intercultural-_Valladares_Laura.pdf Fecha de consulta: 3 de julio de 2016.

Valladares, L. (2012). "La importancia del peritaje cultural: avances, retos y acciones del Colegio de Etnólogos y Antropólogos Sociales AC (CEAS) para la certificación de peritos". Peritaje antropológico en México: Reflexiones teórico metodológicas y experiencias, México: Boletín del Colegio de Etnólogos y Antropólogos Sociales.

Verona, A. (2015). “¿Pluma o espada? La desnaturalización del peritaje antropológico Análisis de seis peritajes". En Guevara Gil A., Verona A. \& Vergara R. (Eds.) El peritaje antropológico. Entre la reflexión y la práctica, Lima: Centro de Investigación, Capacitación y Asesoría Jurídica del Departamento Académico de Derecho (CICAJ).

Villanueva, V. (2014). El ejercicio del peritaje antropológico: perspectivas, retos y alcances de un modelo integral para el dictamen cultural en Chihuahua. (Tesis para obtener el grado de Maestro en Antropología Social). Escuela de Antropología e Historia del Norte de México. Centro de Investigaciones y Estudios Superiores en Antropología Social, Chihuahua, México. 